\title{
Measuring Policy Entitlements at the Micro-Level: Maternity \& Parental Leave in Europe
}

This is an Accepted Manuscript of an article published by Taylor \& Francis in Community, Work and Family on 27/06/2016, available online:

http://www.tandfonline.com/doi/full/10.1080/13668803.2016.1202196

\begin{abstract}
Comparative social policy analysis has been shaped by the measurement of policy as a macro phenomenon. However social policy theories have consistently asserted that policy entitlements vary across class, gender, ethnicity and the life course. This paper synthesises a number of innovations to produce an approach which allows researchers to explore the policy heterogeneity within populations, across populations and over time. Using the example of maternity and parental leave, policy entitlements are identified through the calculation of financial support an individual would receive if they were to have a child, using a combination of legislative rules with representative survey sample. The results reveal far greater heterogeneity in policy entitlements than existing indicators suggest, with considerable implications for research on maternity and parental leave. This approach is not limited to maternity and parental leave benefits and demonstrates a way to explore comparative social policy in greater depth and detail.
\end{abstract}

Keywords: maternity leave; parental leave; policy entitlements; eligibility; measuring policy; EU-SILC

\section{Introduction}


A key concern within comparative social policy has long been the distribution of policy amongst the population. A variety of salient cleavages have been identified in the distribution of policy including gender perspectives (Lewis, 1992), class perspectives (Korpi, Ferrarini, \& Englund, 2013) and labour market positioning (Schwander \& Häusermann, 2013). These perspectives, along with many others, all agree that there is considerable heterogeneity within populations regarding policy entitlements in European Welfare States.

Yet existing empirical indicators of policy entitlements base their calculations either on an average worker or on a typical household type, often with respect to family size and economic activity of the adult members. The characteristics of this standardised household are then used across countries to estimate the extent of particular welfare support this unit would be entitled to. If the entitlements vary due to other factors, for instance depending on number of children or the duration of employment, a reasonable assumption is selected for the purpose of the calculation. These indicators have been used in a number of seminal works in the field of comparative social policy and have contributed a great deal to our empirical understanding of social policies in Europe. However, such policy indicators are unable to fully incorporate the heterogeneity of the population and eventually the policy itself. They are limited in their ability to comprehend how different countries deal with new social risks and cover atypical households or workers (Emmenegger, 2012).

Nevertheless, given the increasing sophistication of data sources and international efforts for comparative policy analysis, it has become increasingly feasible to build on these indicators and produce measures that more accurately reflect the heterogeneity in the population and the 
policy. For example, EUROMOD ${ }^{1}, \mathrm{CWED}^{2}, \mathrm{SCIP} / \mathrm{SPIN}^{3}, \mathrm{OECD}^{\text {Family Database }}$ have all $^{4}$ taken steps to incorporate population heterogeneity within their measures. This paper aims to build on and synthesise the approaches taken by these studies and in doing so develop an approach that enables researchers to fully measure and explore policy variation within and across European populations.

We focus on the specific issue of leave for mothers of very small children (i.e. maternity and parental leaves) as an example case. Despite the narrow focus of our paper, the arguments and conclusions can be applied to a wide variety of policy areas. This method of measuring policy can potentially be expanded to many different forms of social policy measurement and could be a useful tool in both descriptive assessments of social policy but also in the assessment of policy impact. The results of the analysis reveal not only the richness of the data but the heterogeneity in policy entitlements across Europe. Whilst the analysis presented here is only descriptive, the findings suggest that the degree to which policy entitlements are associated with basic life-course, labour market or economic characteristics varies considerably across European welfare states, revealing a complex constellation of policy arrangements previously hidden behind aggregate methods.

Nevertheless, such an approach is not without its limitations and the implications of such a method are considered, including whether the assumptions of such models make theoretical

${ }^{1}$ For details see: https://www.iser.essex.ac.uk/euromod

${ }^{2}$ For details see: http://cwed2.org/

${ }^{3}$ For details see: http://www.sofi.su.se/forskning/tre-forskningsavdelningar/socpol/socialpolicy-indicator-database-spin

${ }^{4}$ For details see: http://www.oecd.org/els/family/database.htm 
sense. The paper concludes with an optimistic assessment of how such an approach could be used to enrich existing micro-data.

\section{Existing approaches}

The measurement of social policy for comparative analysis has traditionally been conducted on the macro level. The most prominent comparative databases for social policy are the Social Citizenship Indicator Programme (SCIP; Korpi \& Palme, 2007) and the Comparative Welfare Entitlements Dataset (CWED; Lyle Scruggs, Jahn, \& Kuitto, 2014) which both focus on three core areas of social policy: pensions, sick pay and unemployment benefits. These datasets have formed the basis of much comparative social policy analysis in recent decades and contributed to our understanding of welfare state variation (Arts \& Gelissen, 2002; Esping-Andersen, 1990; L. Scruggs \& Allan, 2006).

Both CWED and SCIP are built on 'model household types', a methodology that relies upon assumptions about average workers and household characteristics. This process requires careful consideration of assumptions, justified definitions of model family types and the collection of comparable data on average wages and work histories (Lyle Scruggs, 2013). For example, in calculating the benefits associated with sick leave, data producers estimate the average person's labour market income so that they can then calculate the entitlements of this notional average individual. From here a replacement rate, a proportion of income that would be replaced by financial allowances, is produced.

In the sub-field of family policy, which this paper focuses on, a number of comparative datasets have been constructed. They similarly build upon such 'model household types'. Two of the first were the 'Family Policy Database' developed by Gornick, Meyers and Ross (1997) 
and the 'Comparative Family Policy Database' developed by Gauthier (2011). Whilst differing slightly in subject area, the aims and methods of these datasets were very similar to SCIP and CWED in that they employed various assumptions about the population to derive replacement rates and other policy indicators.

Several similar databases have been developed since that formalise this data collection process or extend it to cover new aspects of family policy (Multilinks Database; Keck \& Saraceno, 2011). Yet these datasets also make assumptions about the average worker or the average household before entitlements or replacement rates can be calculated. In employing such 'model household types' the datasets have then been able to reflect some degree of heterogeneity within the population by calculating replacement rates for individuals and households who earn above or below the median wage or who have a differing distribution of employment within the household (OECD, 2014). However, given the similarities in construction and use, the limitations of all these aforementioned datasets are largely shared and consist of four main points to which we will now turn.

\section{Types of Model Households}

The first limitation is that all of the previously mentioned databases make some assumptions about standard household composition. Given that policy is often sensitive to household composition it has long been argued that such an approach overlooks the diversity of household forms, particularly single parents, atypical employment patterns and reconstituted families with complex histories (Orloff, 1993). Although this approach did not originally aspire to provide comprehensive account of the policy entitlements across populations, many of the databases accepted this criticism and have made moves to expand the number of models to which their method is applied. Yet to simply extend the battery of household models might 
not be an ideal solution for some research problems. It raises a question of how such model types contribute to a holistic comparison of two welfare states. Furthermore, this solution does not satisfy the primary concern of the original criticism - it ignores the situation of nonstandard households who are also those for whom policy entitlements are traditionally limited (Ferrarini, Nelson, Korpi, \& Palme, 2013). That is to say that the policy indicator does not adequately reflect the reality for the population. Model household types can be useful in 'controlling' for such population composition issues, but some research question warrant a measure of the population as a whole. Nevertheless, existing policy measures offer little alternative to fill this gap and to assess welfare states also from the perspective of how well they cover needs of their particular populations.

\section{Labour Market Assumptions}

Existing social policy datasets base their measures on average wages and average career duration, ignoring individuals who are self-employed or economically inactive for various reasons. At the same time, the destandardisation of career histories and earnings profiles has been one of the major developments in contemporary labour markets (Emmenegger, 2012). The rise in atypical employment in particular raises questions about the applicability of replacement rates and other social policy indicators which are based on average wages. Heterogeneity amongst the working age population potentially delivers an indicator that reflects the situation for a small proportion of the population who occupy the middle ground but fails to capture the overall structure of earnings and employment histories within the population. A comparative measure in which the replacement rates would be calculated in a way that would allow examining the policy generosity for the whole population together with the variance within the population is still largely missing. 


\section{Static Policy Measurements}

The first two problems are brought about by the estimation of policy coverage based on model household types. Focusing on model households makes the indicators very rigid. It requires big assumptions in order to identify a singular, comparable measure for each welfare state. This need for singularity and comparability enforces a static measurement of the policy instrument itself. For example, in databases that cover unemployment benefits, the duration and conditionality of the benefit receipts need to be clearly defined and therefore reflect a narrow perspective of the policy design. The measures are therefore often taken at two intervals (e.g. immediately after becoming unemployed and at 6 months after becoming unemployed) reflecting the short and the long term rather than an average of the replacement rate over a sustained period of time. Similarly with family policies the indicators tend to refer to policy measures at specific points in time, or ages of the child, which smooth out the subtle variations in policy. A comprehensive measure would incorporate the variation across time and provide a more dynamic indicator of policy design.

\section{Conceptual Ambiguity}

In addition to these issues of rigidity there is a broader issue of what is to be included within a measure of policy benefits. The difference between CWED and SCIP is that CWED is more inclusive in its definition of policy benefits and this is reflected in higher replacement rates in CWED than SCIP (For a discussion of the differences see: Danforth \& Stephens 2013). Given that these two datasets were designed for different uses this is not wholly problematic and in some instances it may be more appropriate to use one definition over another. After all, the question of what should be considered within policy measures is an open ended one (Clasen \& Siegel, 2007). However, from the perspective of a data user this limits operationalization to one 
of two conceptual approaches amongst a much larger number of possibilities. This limitation upon data users is very evident in family policy datasets where the policy ambiguities can be considerable. For example child benefits can be very difficult to measure given the large variety of ways they can be administered and distributed to beneficiaries. What counts as a child benefit is therefore a vexing question for any researcher in the field and the answer is generally informed by the research question and task at hand. Given that the operationalization of policy needs to be sensitive to the context of the research in which it is to be employed, it is not surprising that policy datasets have often applied high standards in cataloguing and documenting the data that is generated and offering detailed descriptions of what was done to create the indices. Such documentation is of great help to researchers but ultimately it falls short of providing researchers with the means to simply adjust and refine the measure to their own requirements without setting about recreating the dataset from scratch. In this instance the ideal would be to develop a dataset that was not only well documented but that was also malleable in the hands of the researcher and policy concepts could be tweaked and refined to make them fit for purpose.

\section{Addressing limitations}

So far we have reflected upon a number of policy databases and outlined some limitations of these datasets. These limitations might be addressed by research infrastructures in the social sciences and more accurate, comprehensive and usable policy indicators might be developed in the future. Before we progress to discuss a potential approach it is important to underline that in the field of maternity and parental leave a number of developments have already been made by researchers that have sought to circumvent the limitations of existing policy datasets. 
For example, Cordula Zabel used imputation methods in her study of first births in the UK to estimate whether individual women were eligible for maternity leave. This allowed her to conduct a flexible micro analysis of maternity leave policy based on a representative sample as opposed to model household types (Zabel, 2009). EUROMOD has taken this further and imputed the tax and benefit position for the eligible individuals in the EU-SILC sample (Immervoll, O’Donoghue, \& Sutherland, 1999). Finally, in a similar initiative the OECD has created a Family Support Calculator (OECD, 2014) which allows researchers to compare policy entitlements depending on the characteristics of individuals or households. This solution provides researchers with flexibility and a means to accommodate the population's heterogeneity within the analysis.

Each of these approaches addresses some but not all of the limitations outlined earlier. Here we seek to build upon these developments and synthesise them into an approach that addresses all of the limitations we identified and enables more effective and usable policy indicators. We aim to produce a policy measure that would capture the policy entitlements of each individual in existing survey data. Such approach not only allows creating aggregated comparable measures for particular populations of interest, but also allows estimating the impact of particular policy measures on people's behaviour.

\section{Data \& Methods}

\section{Data}

We use an example of maternity and parental leave policies to demonstrate the possibilities for an extension of existing comparative social policy measures that would bring more flexibility and accuracy to researchers. We believe that such approach could considerably advance our 
knowledge and understanding of welfare states. To make the policy indicators more meaningful we focus only on the population that is likely to be subjected to such policy measures. It means we only include women in our sample that are of reproductive age and omit those ages with considerably lower probability of conception. Our sample therefore consists of women between the age of 20 and 40. We further limited our sample to women who share a household with their male partners given that having a child is closely related to having a co-resident partner. Women in same sex relationships were excluded from the sample. The sample contains both economically active and economically inactive women. This is to capture the maternity and parental leave designs that recognise and value childcare responsibilities regardless of the employment history of the mother (Knijn \& Kremer, 1997). Including economically inactive women in our sample allows us to capture the nature of the maternity and parental leave designs in their entirety. It also shifts the understanding of the leave policies as a simple break from paid work to a broader understanding that sees the leave policies as a break from the 'obligation' to work.

Even though we restricted our sample in this particular way, our approach gives flexibility to researchers to create their own samples and specify their indicators. Adjusting the specifications would be relatively straightforward and merely entails broadening or narrowing the sample depending on the needs of the research question. For instance, a researcher could incorporate single women in the sample or create an independent sample consisting solely of single women to compare the welfare state support for potentially single mothers. Moreover,

${ }^{5}$ We exclude single women, not because they do not have children but because the circumstances associated with single motherhood and the subsequent policy framework differ considerably to those associated with motherhood within a relationship and so including them may not be appropriate for the evaluation of the policy. Our approach and policy coding can be used to analyse single mothers. 
the individual leave measures can be freely combined or compared separately as will be shown later on.

Our sample of women was taken from the longitudinal EU-SILC database for years 2006-2009 and contains 20,697 individuals from 27 European countries. Germany and Portugal were excluded from the sample due to a small number of repeated measures and methodological issues. The remaining EU member states were included and were joined by Norway and Iceland.

\section{Imputing Policy Entitlements}

The first step in the analysis was the collection of detailed information on each country's maternity and parental leave policy in each year. The primary sources were the Annual Reviews produced by the International Network for Leave Policy and Research (LP\&R) and the Mutual Information System on Social Protection (MISSOC) database. The information on leave legislation was collected for those time points that correspond with the EU-SILC data collection (2006-2009). This means that if the policy changed within a country during the period of study, the indicator would reflect that. This information was then used to assess whether each of the 20,697 women in our sample would be eligible for maternity and parental leave were they to have a(nother) child. Each woman's financial compensation and leave duration was then calculated based on the method described in the legislation.

In our analysis, we created an indicator of the total leave duration, a combination of maternity leave duration before birth, after birth and subsequent parental leave for each individual in the survey measured in weeks. In case an individual is not entitled to one of the policies (e.g. not eligible for maternity leave but eligible for parental leave), the duration for that particular policy is coded as 0 weeks. Consequently, individuals who are not entitled to any of the leave schemes 11 
were coded as being entitled to a leave duration of 0 weeks. In countries where the leave legislation offers financial allowances to parents who are not economically active, the leave duration is understood as the time period during which the allowance is provided. Similarly, in countries where parents may freely choose duration of leave or duration of the benefit payment, we used the most generous option. In cases where the parental leave is a family entitlement and as such allows parents to share the parental leave as they wish, the whole duration of the parental leave, which is not specifically dedicated either to the mother or the father, was assigned to the woman.

The same approach was adopted to calculate the total leave benefits. The financial compensation for maternity and parental leave was again combined into one measure and adjusted to produce a weekly average amount for the duration over which it is paid. Financial compensation in majority of European countries overlaps with the duration of leave. But some countries provide financial benefits from the leave scheme for either longer periods than the determined leave duration, or shorter. In cases where the duration of benefit payments was longer than that of leave, the total time for which the respondent would be eligible for benefits was taken to be the total leave duration. To produce an average weekly benefit that would capture the average amount of financial support over the total period of leave, the amount of benefits corresponding with individual leave entitlements had to be weighted for the time over which this benefit is paid. We therefore first calculated the total leave benefit as a weighted average (i.e. total of individual weekly benefits multiplied by the duration of the appropriate leave).

The Average Weekly Benefit (AWB) was then calculated as follows:

$$
\text { AWB }=\frac{\text { Total Leave Benefits }}{\text { Total Leave Duration }}
$$


The estimated value of the $A W B$ was then compared to the woman's average weekly income, defined as gross personal income inclusive of benefits and non-earned income over an average week in the last 12 months. The final Compensation Rate measure therefore reflects the change in the woman's income if she would decide to have a child and take the leave:

$$
\text { Compensation Rate }=\frac{\text { Average Weekly Benefit }}{\text { Average Weekly Income }}
$$

To reflect the change in cases where a woman has an average weekly income of 0 but despite that is entitled to financial help from the leave scheme, null incomes were given a compensation rate of 1 if they were eligible for any financial compensation and 0 if they were entitled to no financial compensation. This measure therefore differs from a replacement rate in that it is not only referring to those who are currently in employment. For this reason, it is referred to here as compensation rate rather than a replacement rate. This is the measure which is examined in the remainder of this paper and used as an example of deriving policy indicators from a combination of macro policy data and micro survey data. The syntax representing the policy coding is available upon request and can be adapted to samples that deviate from those presented here and adjusted for alternative research questions.

\section{Strengths}

By calculating these measures for a random sample of women within a country, detailed analysis can be conducted on the nature of the policy within each country. This approach has several advantages over traditional comparative analysis of maternity and parental leave which either used datasets such as those mentioned earlier in the paper (Gauthier, 2011; Gornick, Meyers and Ross, 1997), simply reviewed the individual designs (Haas, 2003; Wall \& Escobedo, 2013) or empirically assessed similarities through various indices (Boca \& Wetzels, 
2007; Ray, Gornick, \& Schmitt, 2010). Such approaches necessarily lead to a reduction of within country variation.

Firstly, modelling maternity and parental leave legislation on micro-level data allows us to take into consideration various conditions that shape the leave entitlements but which until now were largely ignored. The most prevalent conditions that are omitted from the policy indicators of replacement rates are the 'ceilings' and 'floors' that determine the maximum and minimum level of benefits that could be drawn by their recipients. Depending on their setting, the limits can significantly influence the actual proportion of previous earnings each individual is compensated on. Consequently, the legislatively determined replacement rate does not have to apply for all the recipients as assumed by existing replacement rate indicators.

Secondly, the approach was able to take into consideration the economic status of the individuals and distinguish economically inactive or unemployed individuals who would be entitled to financial compensation for the time spent on leave. Additional conditions that were included in the modelling of leave entitlements were the duration of employment, type of contract, region of residence, number of children, adjustments and reforms in the leave systems and differences in payment over the course of the leave.

A third advantage of this approach is that the indicators effectively measure post-birth policy support before the event actually occurs. This approach avoids possible selection effects which cannot be accounted for in the case of measuring the policy use such as the approach in EUROMOD. In EUROMOD, the benefit levels are only calculated for those who have experienced and event rather than all those who are exposed to the risk of an event. If women who have poor policy entitlements with regards to maternity leave are avoiding parenthood, then there would be an upward bias on the types of estimates provided by EUROMOD as 14 
their figures are for mothers only. This is because EUROMOD is not designed to measure exante policy entitlements. The measure presented here is therefore capturing policy entitlements rather than benefit provision.

Finally, the imputation method applied in this paper creates an opportunity to assign policy values to each individual in the survey and understand the policy entitlements in their particular contexts. Until recently policy measures and indicators have been the reserve domain of macro-level research designs and more recently multilevel modelling. This approach extends this by laying the macro-level policy information over the population observed in survey research. Although similar approaches have been adopted before in different studies (Boll, Leppin, \& Reich, 2013; Vaalavuo, 2013; Zabel, 2009), this study increases the span of its application and introduces it into a cross-national comparison of welfare support.

\section{Limitations}

Whilst we believe the approach builds on the existing indicators, it does have number of limitations in its use which researchers should be aware of. A potential methodological issue with this approach is that it increases the potential measurement error within the indicator. By drawing on two sources of information rather than one, the measure becomes susceptible to all the potential sources of sampling bias and measurement error that are part of survey research or legislative information. Survey research has improved in quality but surveys such as the EU-SILC still have sampling and measurement issues that are yet to be fully resolved. Such problems require researchers using such measures to be familiar with the problems inherent within survey research. For example, our policy indicators were calculated with appropriate cross-sectional weights but an awareness of such procedures is necessary for inference as well as the actual construction of indicators. 
Similarly, surveys have measurement errors on every instrument including key indicators like income and education level. These instruments are under constant improvement but they still limit the quality of the indicator produced. For example, the measure of net household income in EU-SILC is poor with a high level of missing values and signs of measurement error. Due to this, gross individual income was used in this analysis. However, this is not desirable from a policy perspective given that policy designs often treat tax differently with benefits in some countries exempted from tax whilst they are not in others and it would therefore be desirable to use the form of income used in the calculation of benefits in each country.

Furthermore, a few variables used in the calculation of policy entitlement were either poorly measured and in very small number of cases were missing altogether. First, the respondent's union membership and corresponding collective agreement which influence entitlements for instance in Norway. Second, there is an absence of information about whether the respondent is employed in the private or public sector ${ }^{6}$. Third, respondents' work histories were only partial in many cases and so inferences had to be made about their degree of work experience in countries where this affected individuals' entitlements ${ }^{7}$. The inclusion of such indicators would add a further degree of detail and accuracy to the measures. Finally, given the high data demands both in terms of comprehensive comparable survey data and systematically collected information on social policies, there is limited geographical and temporal coverage for now. It should be noted however that whilst limitations exist within such survey data, they still represent a rich source of data that can significantly enhance the measurement of policy.

${ }^{6}$ In case the legislation specified different rules for individuals working in the public and private sector, we treated all individuals in our sample as working in the private sector.

7 The employment history in EU-SILC covers only 12 months, which represents certain limitation in countries which that several months of employment over period of time that is longer than one year. This is, for instance, the case of Spain. 


\section{Analysis}

In this paper we would like to focus primarily on the aggregated indicator of financial compensation from the maternity and parental leave policy, which we created from the imputed policy information on an individual level. To examine the proposed new aggregated measure, the analysis will start by comparing it with the existing replacement rate measure in the OECD Family Database. This will allow for deviations between the two measures to be identified and explored. Once this comparison has been made, our indicator will also be examined from other perspectives that are relevant to social policy research.

\section{Comparison with the OECD Family Database}

The OECD provides several indicators of child-related leave replacement rates which are the closest and most comprehensive measures currently available (OECD Family Database, 2015). Three measures are referring to maternity, parental and father-specific leave replacement rates that are compared to average gross earnings. Two alternative measures compare the payment benefits to net household income - one combines maternity and paternity leave, the second one refers to parental leave. In this paper we will compare our compensation rate indicator to the maternity and parental leave replacement rates produced by the OECD.

The OECD indicators of maternity and parental leave are built on a model household with two earners who received national average earnings for their gender prior to the birth and who have a newborn child. The indicator assumes that both partners were employed for sufficiently long time in order to be eligible for leave. As mentioned in section 2, this gives a limited insight into the nature of the policy. To circumvent this, the OECD also calculates the rates for households where the two earners earn $50 \%$ and $150 \%$ of their respective average wages 
(OECD Family Database, 2015). We contrast this replacement rate indicator with our measure of compensation rate ${ }^{8}$. To produce better comparison between the two measures we also calculate the compensation rate for people in co-residential relationship and married. But there are no further restrictions on the household characteristics such as the number of children, earnings or employment status; or the policy design (for exceptions see Limitations in the Data \& Methods section). As it is apparent from Figures 1 and 2, omitting these restrictions and applying the leave eligibility conditions on the whole population of cohabiting women produce significant differences between the two indicators.

[FIGURE 1 ABOUT HERE]

Our compensation rate therefore includes women who are self-employed, out of work, in education or in part-time employment - women who are omitted from the OECD measure. The substantial differences between the OECD replacement rates and our compensation rate are therefore caused by the fact that these individuals are treated very differently by different policy designs.

\section{[FIGURE 2 ABOUT HERE]}

However, to validate whether the difference is due to the inclusion of these women, the compensation rate was recalculated only for women in full-time employment in order to be more comparable with the measure used by the OECD. When this was done, the compensation indicator was much closer to the OECD measure (not shown, available upon request).

${ }^{8}$ Unfortunately, the OECD Family Database provides only most recent indicators and does not keep the data from previous years. Therefore, we can only compare the OECD most recent replacement rates (2014) with our most recent compensation rates (2009). 
To explore these differences further we can look at an example of two countries that have similar scores on the OECD indicator. The maternity leave compensation rate for Poland is 0.53 whilst the replacement rate produced by the OECD is 1.00 . This discrepancy is largely due to the lack of benefits offered as part of maternity leave for women who are either out of work, in education or are self-employed. If one looks at the OECD figures it appears as though Poland has maternity leave benefits similar to those of France, with both the countries reporting replacement rates of 1.00 . This is certainly true as the legislation in both countries compensate mothers on maternity leave for $100 \%$ of their foregone earnings. However, the legislation specifies further conditions that makes the maternity leave systems in Poland and France distinct. For instance, whilst in Poland the maternity leave is available only to employed women, in France this option is available also to self-employed mothers. On top of the 100\% replacement rate specified in both countries, France also provides minimum and maximum threshold on benefit payment. When these conditions are taken into consideration using our compensation rate, Poland has a rate of just 0.53 and France has a rate of 0.82 , reflecting very different leave designs. In short, the replacement rate provided by the OECD only covers a subsection of the population whereas the compensation rate calculated here reflects how the policy affects the actual population within the country.

\section{Variation within Countries}

Having established that our measure is more comprehensive than the measure used by the OECD, the additional advantages of a survey based approach to compensation rates can be considered. To do this we look at how our measure enables researchers to examine the

distribution of the policy within countries, over time and across a number of socio-economic variables. Figure 3 shows the percentiles for the compensation rate at 10\%, 25\%, 50\%, 75\% 
and $90 \%$ of the population. This indicator refers to the pooled maternity and parental leave information. The results reveal striking variation in the nature of policies across Europe. For example, we can look at the policy provision in Lithuania where the percentiles are indistinguishable because almost everyone receives high levels of compensation during the time that they are on maternity or parental leave. When compared with Luxembourg the differences are substantial. Here the policy is still generous but because it consists of a flat rate benefit, the compensation rate varies substantially across the population. $10 \%$ of the sample in Luxembourg would be eligible for a compensation rate of close to 0 where as another $10 \%$ would be eligible for 50\% more than their current income. Our measure therefore captures variation in policy entitlement that would otherwise be lost.

[FIGURE 3 ABOUT HERE]

\section{Policy Change}

The distribution of a policy across a population is particularly interesting when observed over time. The EU-SILC has been running for almost a decade and there have been a number of changes in policy across Europe during this time period. This proposed method of measuring policy is particularly useful in understanding the impact of such reforms, as can be witnessed in Figure 4, which depicts the reform of Swedish maternity and parental leave in 2007. We have chosen Sweden as an example given that it is one country which had meaningful reform of childcare leave during the period for which data is available. In the majority of the other countries, the compensation rates are largely stable. In 2004-06 the policy in Sweden was generous, benefits were linked to earnings and were tempered by specific ceilings and floors. However high earners had a low replacement rate given that their nominal benefits were capped and they would therefore receive a smaller percentage of their earnings than the rest of 
the population. In 2007 however the cap on the nominal benefits was increased and so high earners who had previously hit the ceiling in terms of nominal benefits now had a higher replacement rate (Moss, 2007). This can be seen in the narrowing of the replacement rate distribution, particularly in the increase in the replacement rate of the bottom $5 \%$. This greatly shifted the distribution of the compensation rate as those on high incomes were now eligible for greater benefits during parental leave resulting in greater compensation rates for those who had previously had much lower compensation rates. Whilst these movements may not appear dramatic, they reflect the impact of a very subtle change in policy parameters on the overall levels of policy entitlement.

[FIGURE 4 ABOUT HERE]

\section{Micro Indicator}

Whilst looking at the distribution in such a way allows for a greater understanding of a policy design than existing indicators based on model family forms provide, this analysis has yet to fully demonstrate the granularity of policy analysis and comparative assessment that is achievable through this method. For example, Figure 5 plots women's earnings against their expected benefits and thus illustrates the extent to which the compensation rate relates to earnings. Furthermore, it illustrates this for all 27 countries for which data is available and the shapes represented by the resulting plots tell us much about the design of maternity and parental leave policy in Europe. The black diagonal line represents a compensation rate of 1 in that it is the point where earnings are equal to benefit levels. By assessing the extent to which dots deviate from this line we are able to deduce the extent to which benefits are related to earnings within a given country. For example, in Norway benefits are closely tied to earnings. In Denmark, by contrast, a cap on benefits exists which ensures that the relationship between 
earnings and benefits is broken beyond a certain level. It is also possible to make out constellations of policies targeted at particular groups who are generally found to be on a low income. For example, in Belgium students on maternity or parental leave receive benefits which far exceed what they would otherwise be earning during their studies - their values can be seen in the top left of the Belgian figure. This simple graphic illustration therefore further uncovers the other dimensions of the policy measures hidden in the aggregated data previously presented.

[FIGURE 5 ABOUT HERE]

\section{Policies and covariates}

Given that we have individual level information of the respondents for whom we have calculated policy entitlements it also becomes possible to ask questions of this data which relate to any other covariate within the original survey.

In family policy research, one question that has been prominent is whether policy is closely associated with the life-course in various countries. By examining the policy entitlements across a covariate such as age it is possible to consider such a question. Figure 6 shows the compensation rate for cohabiting individuals at each year of age between 20 and 40 . What is immediately clear is that there are very distinct life-course patterns to policy provision. In a number of countries, policy provision increases with age, in some it declines and in others it remains steady. It is also possible to identify particular ages at which policy entitlements abruptly change yet no singular pattern emerges. For example, in Lithuania, the close ties between labour market earnings and benefits ensure that there is little variation across age groups using this measure. Yet in Slovakia by contrast we see something quite interesting. Here the flat rate benefits mean that the compensation rate actually starts to decrease with age as 22 
those earning enough to hit the cap are generally older. The opposite is the case in France where benefits are dependent on having worked for a specified period of time. This ensures that higher rates of compensation are only accessible to those who have been working for some time and who are therefore generally older. This could be repeated with any number of covariates such as sector of employment, educational level, socio-economic status or region. It is therefore far more open to interrogation, examination and analysis than previous measures of policies.

[FIGURE 6 ABOUT HERE]

\section{Discussion \& Conclusions}

This paper set out to build on existing measures of parental and maternity leave to produce a set of measures that more accurately reflected the heterogeneity within the population. However, it needs to be pointed out that our aim is not to produce static indicators that would be available to researchers. Instead we would like our approach to become an integrated part of existing surveys. Its biggest strength lies in the policy values being assigned to each individual in the survey and in the freedom such approach brings to the researchers. The individual values can be freely aggregated to suit the purpose of a particular research question. But the variation in the policy distribution can be studied as well. Alternatively, the individualised policy values can be also used in a policy impact studies. Therefore, our paper did not attempt to present a new policy measure but rather a new possibility of studying the welfare state and policy support. The analysis of the measure illustrated that the existing model household type approach excluded a large proportion of the population who generally have poorer policy entitlements. It also demonstrated that family policies vary considerably across the population and are interrelated with a number of other key socio-economic 
characteristics. Given this we conclude that the presented measure more accurately reflects parental and maternity leave policy entitlements in Europe. The indications from even the limited descriptive analysis presented here suggest that the picture of policy entitlements for maternity and parental leave previously drawn using aggregated data was over simplified and neglected variations with the population. What's more, given the use of a model household type approach in other areas of social policy, we anticipate that the use of survey based indicators could greatly improve policy measurement in a number of areas.

More than two decades ago comparative social policy was greatly advanced by the development of comparable policy measures like those in SCIP and CWED, enabling the development of welfare state typologies that have enriched the study of European Welfare States. Since then many of the key theoretical developments in comparative social policy have highlighted that such measures are limited in their ability to capture the heterogeneity of policy entitlements within countries and the reductive nature of the associated typologies. The approach detailed in this paper allows researchers to fully incorporate this heterogeneity in a comparative setting. It is possible to see how policy entitlements are stratified by socioeconomic status in each European country or how policy entitlements evolve over the lifecourse. Such granularity in the empirical data enables increasingly complex theories of comparative social policy to be tested, potentially revealing new constellations of social policies within Europe and an enhanced understanding of European Welfare States.

The compensation rate calculated based upon the analysis of survey data is not only a more accurate measure of a policy's design, but it also allows researchers to further interrogate and examine policy designs within European welfare states. Given the tradition of using replacement rates to measure the extent to which policies decommodify individuals, adopting 
this approach could lead to a re-evaluation of comparisons between European welfare states, especially given that the reasons for discrepancies between the two measures are also applicable to unemployment benefits, sick pay and pensions.

The analysis has shown that using a representative sample for the measurement of policy enables new insights into policy design and coverage. However, it is important to note that this approach does have some limitations and its use is not always appropriate. For example, model household forms are prominent concepts within theories of social policy such as the dual earner model or male breadwinner model (Lewis, 2001). Existing data sources may therefore be a more relevant, pertinent and appropriate social policy measure when assessing these theories. Yet the approach outlined here can also provide empirical validation of such concepts and their use in theories of comparative social policy. Model household forms and the extent to which they can be found within the wider population could provide a stronger empirical basis for such analysis, particularly in their cross-national equivalence. The approach offered here allows for this as researchers are able to restrict the sample to those that fit within the broader concept of their model household type and examine the extent to which the resulting sample is homogenous or in line with the conceptualization.

Another reason that this method might be considered inappropriate for certain tasks is that it focuses on the outcome of a policy design rather than the policy design itself. For example, if a population has a lot of part time workers the compensation rate measure will be heavily influenced by how the design affects part time individuals. That is to say there is a compositional effect on the policy measure. In some instances, this can be useful, particularly when attempting to evaluate how well the policy satisfies the needs of the population in a given country or how it mitigates the social risks for particular social groups. If, by contrast, 
the research question is orientated on the design of the policy itself then it could be argued that existing datasets would be more appropriate as they compare like with like.

Compositional effects however also cause issues when evaluating outcomes. The use of a representative sample instead of an ideal household type leads to the inclusion of individuals who are not necessarily the intended targets of a policy. Using the method detailed in this paper, the compensation rate would be calculated for the entire adult working population, yet some policies such as unemployment benefits are designed primarily for those particularly at risk. It may therefore be inappropriate to evaluate unemployment benefits by considering the policy entitlements of a high income individual and a low income individual on equal terms and weighting respondents may be appropriate.

Whilst this approach is not without its limitations and demands conceptual clarity from the researcher, the analysis has shown that the advantages and applications that come with it are considerable, enabling more nuanced and accurate measurement of family policy across countries. By imputing the actual policy position of individuals using high quality survey data it is possible to produce more accurate and insightful observations regarding social policies across countries and over time. Future research should focus on standardising this methodological approach and allowing for the integration of existing social policy infrastructures who provide information on policy design and legal frameworks such as the Mutual Information System on Social Protection (MISSOC) with survey infrastructures such as the EU-SILC and the European Quality of Life Survey.

\section{References}

Arts, W., \& Gelissen, J. (2002). Three worlds of welfare capitalism or more? A state-of-the-art report. Journal of European Social Policy, 12(2), 137-158.

Boca, D. Del, \& Wetzels, C. (2007). Social Policies, Labour Markets and Motherhood: A Comparative Analysis of European Countries. Cambridge University Press. 
Boll, C., Leppin, J., \& Reich, N. (2013). Paternal childcare and parental leave policies: evidence from industrialized countries. Review of Economics of the Household, 12(1), 129-158.

Clasen, J., \& Siegel, N. A. (2007). Investigating Welfare State Change: The "Dependent Variable Problem" in Comparative Analysis. Edward Elgar.

Danforth, B., \& Stephens, J. D. (2013). Measuring social citizenship: achievements and future challenges. Journal of European Public Policy, 20(9), 1285-1298.

Emmenegger, P. (2012). The age of dualization: the changing face of inequality in deindustrializing societies. Oxford University Press.

Esping-Andersen, G. (1990). The Three World of Welfare Capitalism. Princeton, NJ: Princeton University Press.

Ferrarini, T., Nelson, K., Korpi, W., \& Palme, J. (2013). Social citizenship rights and social insurance replacement rate validity: pitfalls and possibilities. Journal of European Public Policy, 20(9), 1251-1266.

Gauthier, A. H. (2011). Comparative Family Policy Database, Version 3 [computer file]. Netherlands Interdisciplinary Demographic Institute and Max Planck Institute for Demographic Research (distributors). Retrieved from www.demogr.mpg.de

Gornick, J. C., Meyers, M. K., \& Ross, K. E. (1997). The Family Policy Database. Journal of European Social Policy, 7(1), 45-70.

Haas, L. (2003). Parental Leave and Gender Equality: Lessons from the European Union. Review of Policy Research, 20(1), 89-114.

Immervoll, H., O’Donoghue, C., \& Sutherland, H. (1999). An introduction to EUROMOD. EUROMOD Working Paper, (1), 1-21.

Keck, W., \& Saraceno, C. (2011). Database on Intergenerational Policy Indicators: Methodological Report. Version 2.1. Retrieved from http://multilinks-database.wzb.eu/pdf/Methodologicalreport.pdf

Knijn, T., \& Kremer, M. (1997). Gender and the Caring Dimension of Welfare States: Toward Inclusive Citizenship. Social Politics, 4(3), 328-361.

Korpi, W., Ferrarini, T., \& Englund, S. (2013). Women’s Opportunities under Different Family Policy Constellations: Gender, Class, and Inequality Tradeoffs in Western Countries Reexamined. Social Politics, 20(1), 1-40.

Korpi, W., \& Palme, J. (2007). The Social Citizenship Indicator Program (SCIP).

Lewis, J. (1992). Gender and the Development of Welfare Regimes. Journal of European Social Policy, 2(3), 159-173.

Lewis, J. (2001). The Decline of the Male Breadwinner Model: Implications for Work and Care. Social Politics, 8(2), 152-169.

Moss, P. (2007). Leave Policies and Related International Review of Leave Policies and Related Research 2007. International Network on Parental Leave and Research. Retrieved from http://www.leavenetwork.org/lp_and_r_reports/

OECD. (2014). OECD Family Database: the Family Support Calculator. Retrieved December 3, 2014, from http://www.oecd.org/els/soc/oecdfamilydatabasethefamilysupportcalculator.htm\#calcul ator

OECD Family Database. (2015). PF2.4: Parental leave replacement rates. Paris: OECD - Social Policy Division - Directorate of Employment, Labour and Social Affairs. Retrieved from www.oecd.org/social/family/database.htm

Orloff, A. (1993). Gender and the Social Rights of Citizenship : The Comparative Analysis of Gender Relations and Welfare States. American Sociological Review, 58(3), 303-328. 
Ray, R., Gornick, J. C., \& Schmitt, J. (2010). Who cares? Assessing generosity and gender equality in parental leave policy designs in 21 countries. Journal of European Social Policy, 20(3), 196-216.

Schwander, H., \& Häusermann, S. (2013). Who is in and who is out? A risk-based conceptualization of insiders and outsiders. Journal of European Social Policy, 23(3), 248-269.

Scruggs, L. (2013). Measuring and validating social program replacement rates. Journal of European Public Policy, 20(9), 1267-1284.

Scruggs, L., \& Allan, J. P. (2006). Welfare-state decommodification in 18 OECD countries: a replication and revision. Journal of European Social Policy, 16(1), 55-72.

Scruggs, L., Jahn, D., \& Kuitto, K. (2014). Comparative Welfare Entitlements Dataset 2. Version 2014-03.

Vaalavuo, M. (2013). The Redistributive Impact of "Old" and "New" Social Spending. Journal of Social Policy, 42(03), 513-539.

Wall, K., \& Escobedo, A. (2013). Parental Leave Policies, Gender Equity and Family WellBeing in Europe: A Comparative Perspective. In A. Moreno Minguez (Ed.), Family WellBeing: European Perspectives (Vol. 49, pp. 103-129). Dordrecht: Springer Netherlands.

Zabel, C. (2009). Eligibility for Maternity Leave and First Birth Timing in Great Britain. Population Research and Policy Review, 28(3), 251-270. 


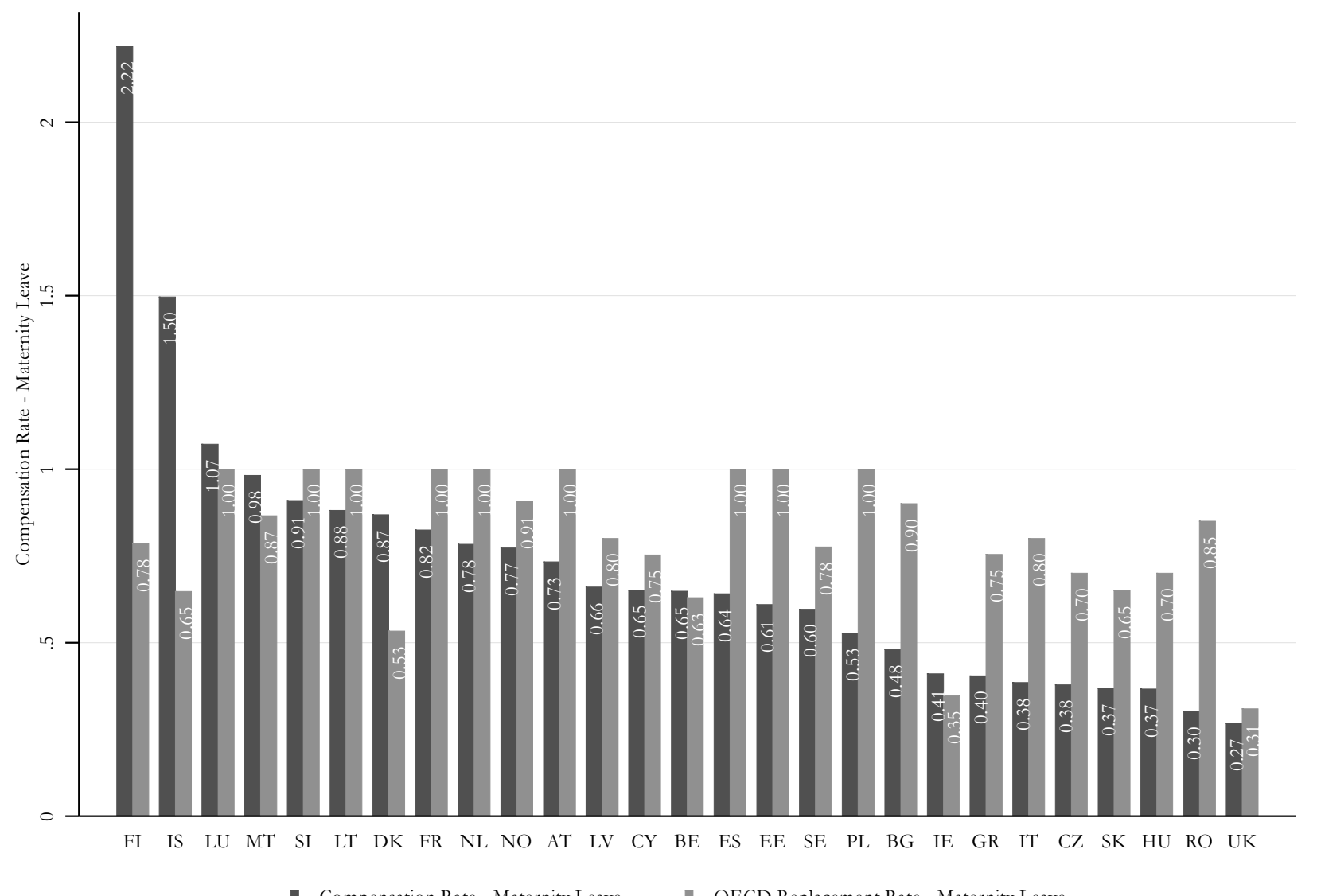

Figure 1 - The Maternity Compensation Rate (2009) and the OECD Maternity Replacement Rate (2014)

Source: OECD Family Policy Database, 2014; EU-SILC, LP®R Annual Review, MISSOC 2009. Note: Compensation rate based on authors' own calculations. AT: Austria; BE: Belgium; BG: Bulgaria; CY: Cyprus; CZ: Czech Republic; DK: Denmark; EE: Estonia; ES: Spain; FI: Finland; FR: France; GR; Greece; HU: Hungary; IE: Ireland; IS: Iceland; IT: Italy; LT: Lithuania; LU: Luxembourg; LV: Latvia; MT: Malta; NL: Netherlands; NO: Norway; PL: Poland; RO: Romania; SE: Sweden; SI: Slovenia; SK: Slovakia: UK: United Kingdom 


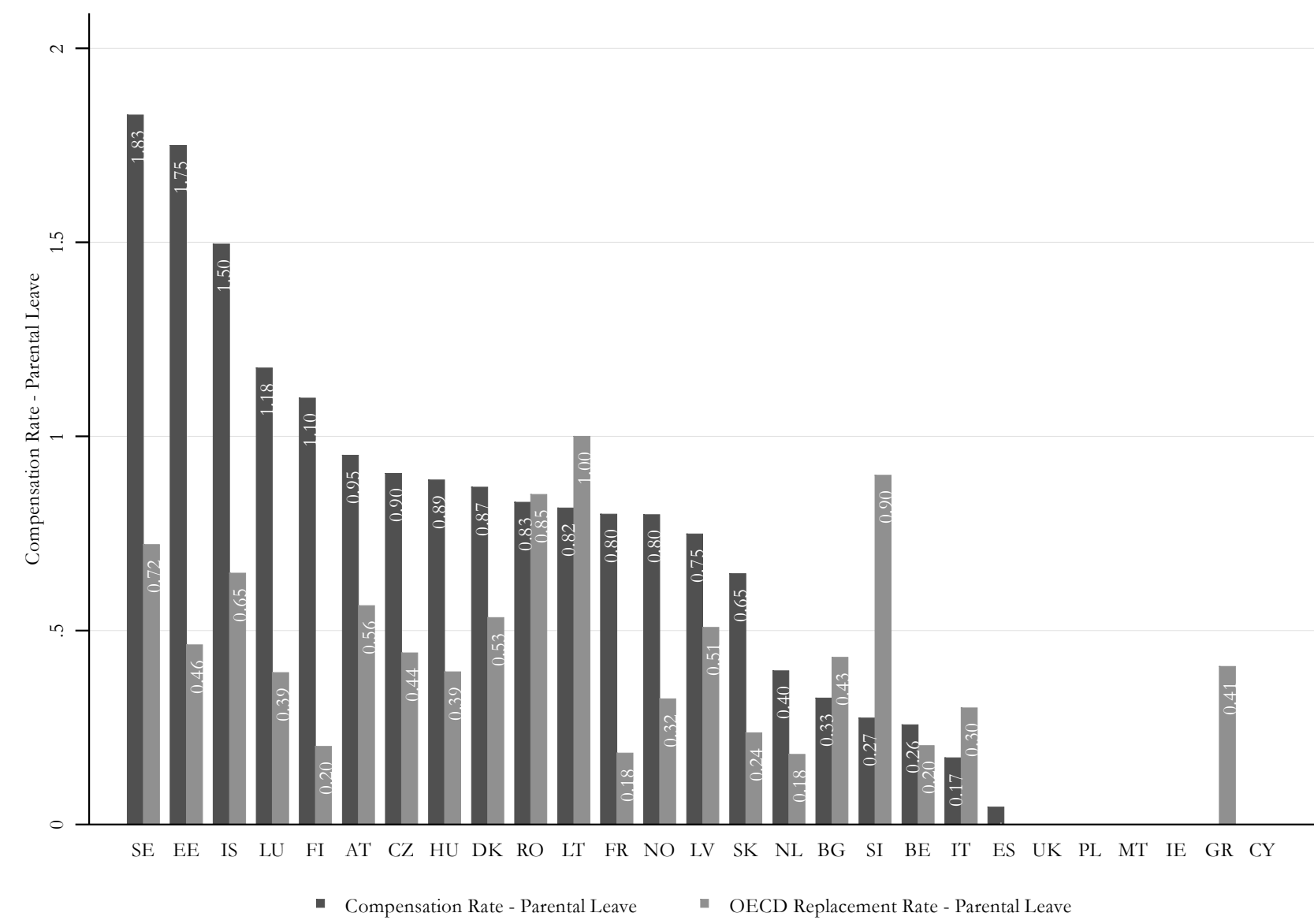

Figure 2 The Parental Compensation Rate (2009) and the OECD Parental Replacement Rate (2014)

Source: OECD Family Policy Database, 2014; EU-SILC, LP\&R Annual Review, MISSOC 2009. Note: Compensation rate based on authors' own calculations. For country abbreviations see Figure 1. 


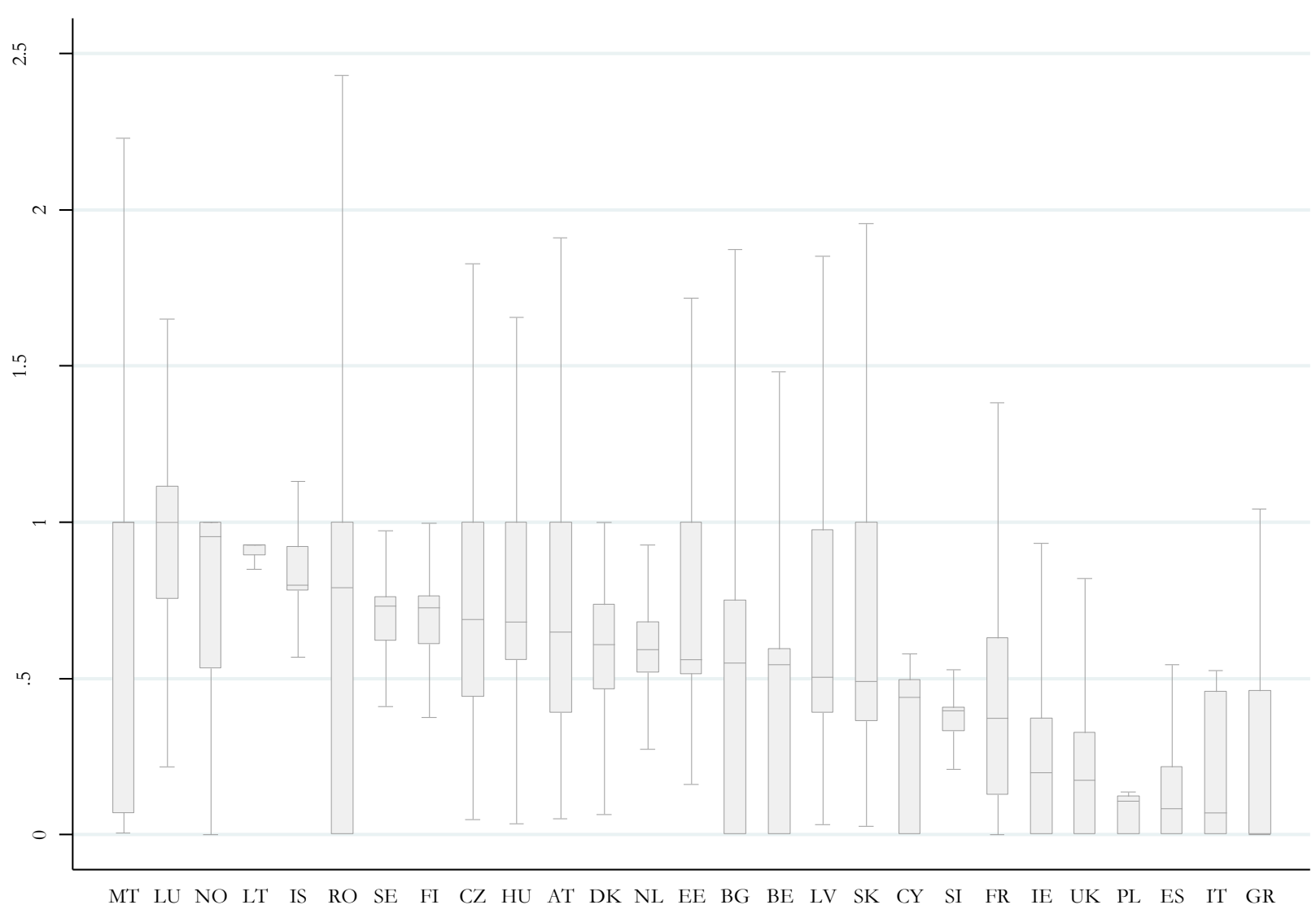

Figure 3 - Within Country variation using the median, 10th, 25th, 75th \& 90th percentiles for Compensation Rates (2009) Source: EU-SILC \& Parental Leave Network, 2014. Note: Authors own calculations For country abbreviations see Figure 1. 


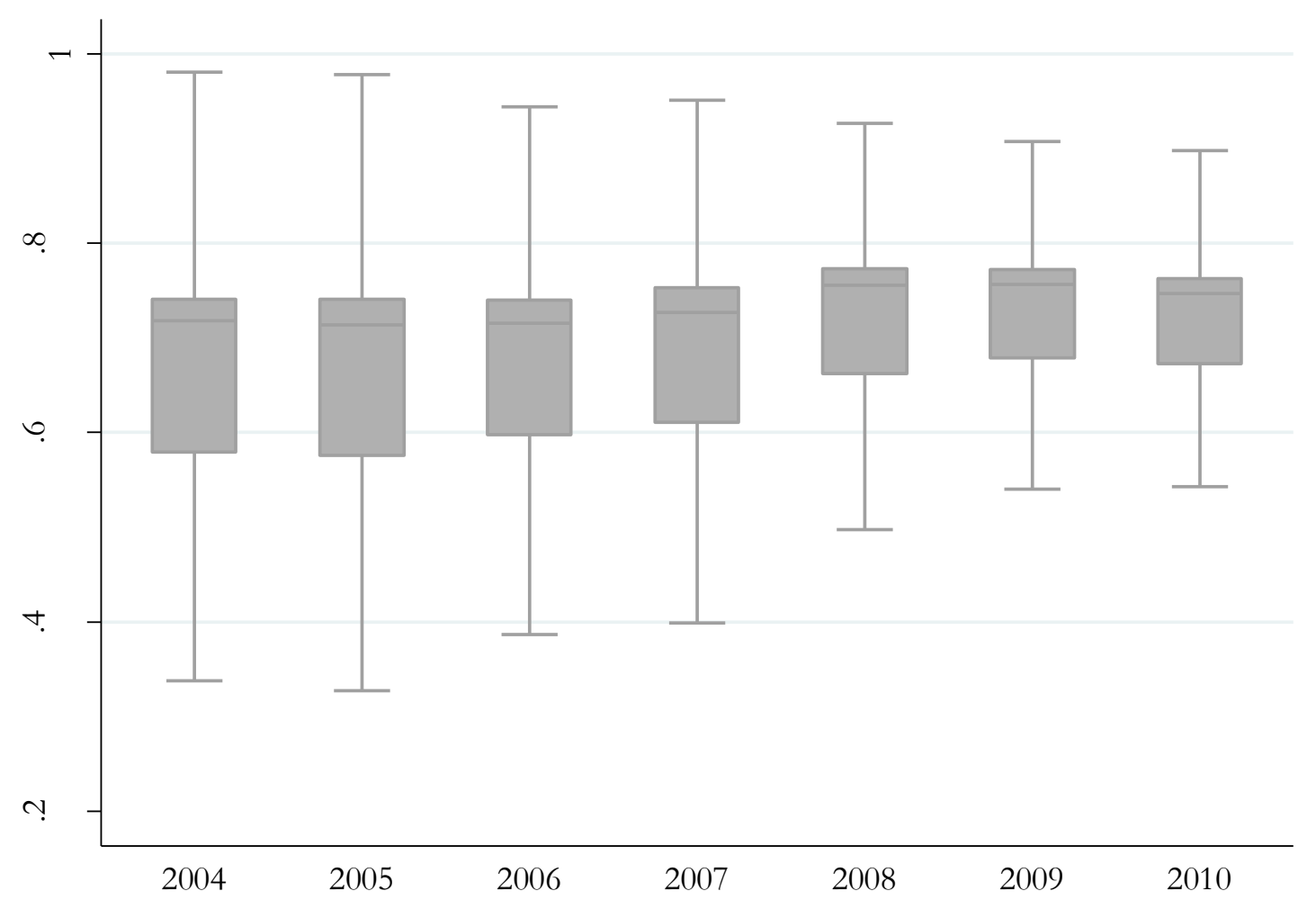

Figure 4 - Compensation Rates in Sweden 2004-10

Source: EU-SILC \& Parental Leave Network, 2014, Authors own calculations. Note: Whiskers are at 5\% and 95\%, the boxes are at 25\% and $75 \%$ and the line in the middle represents the median. 

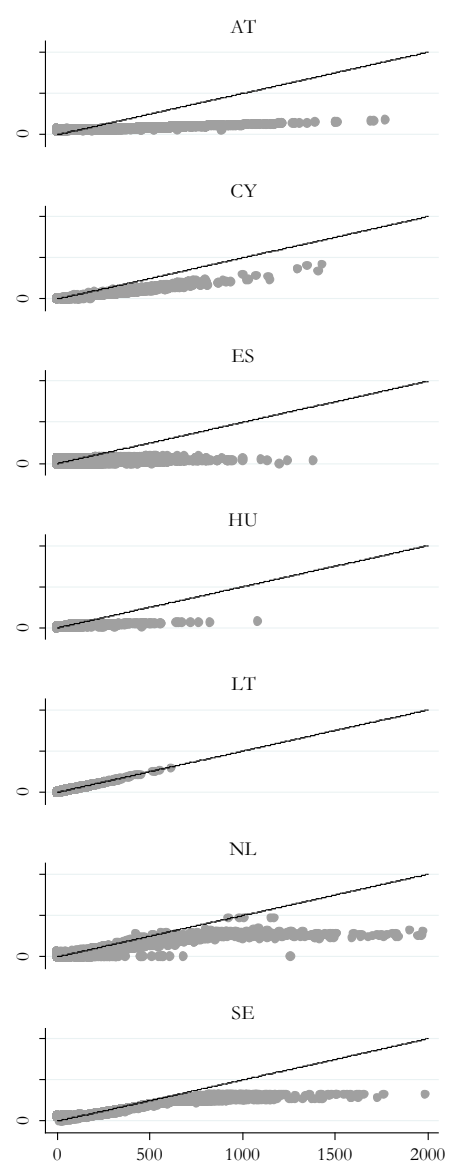
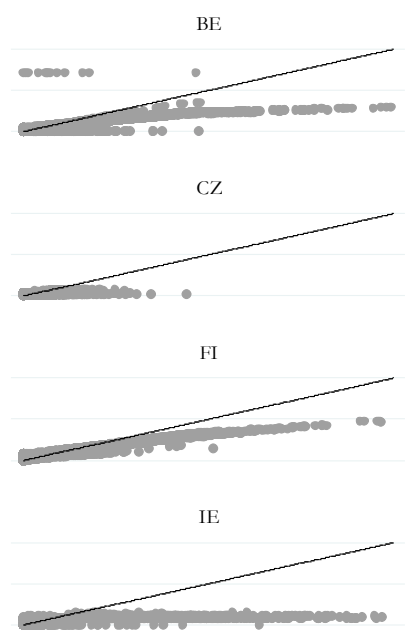

$\mathrm{LU}$

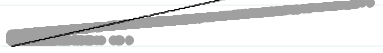

NO
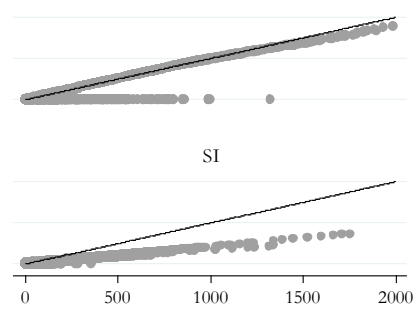
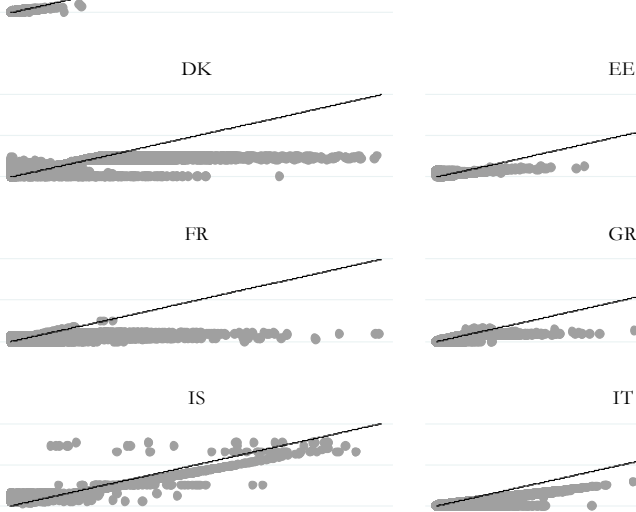

$\mathrm{LV}$
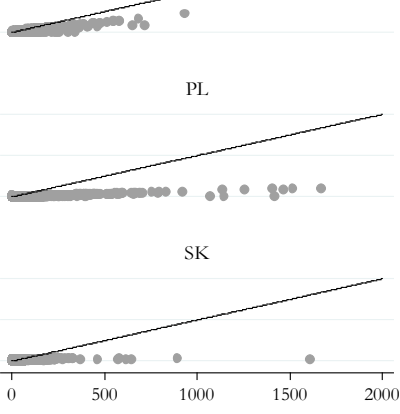

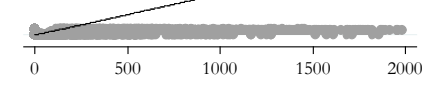

Figure 5 - Income from current earnings and expected benefits in Euro's (2009)

Source: EU-SILC \& Parental Leave Network, 2014. Notes: Autbors own calculations. For abbreviations see Figure 1. 


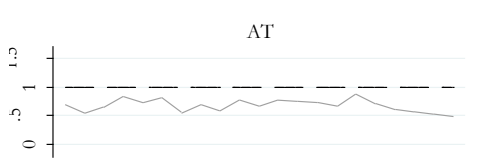

CY

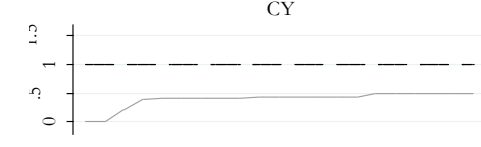

ES

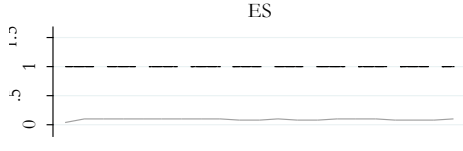

$\mathrm{HU}$

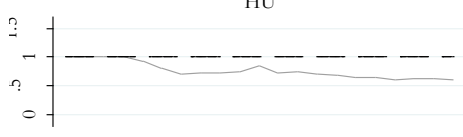

LT

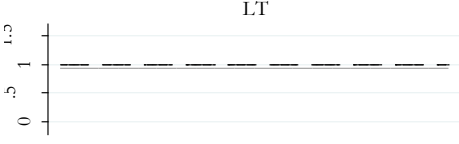

NL

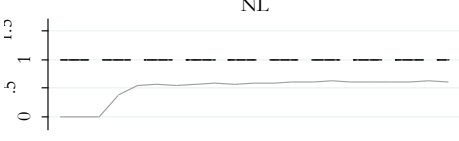

SE

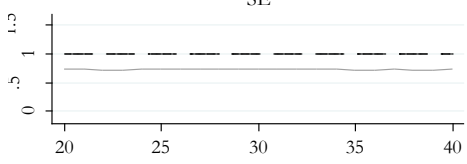

BE

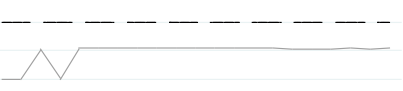

CZ

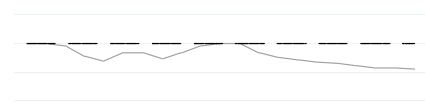

FI

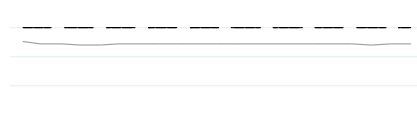

IE
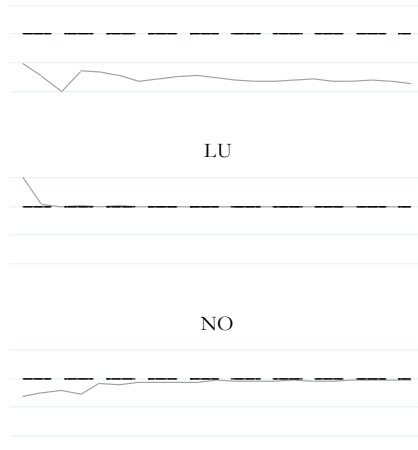

SI

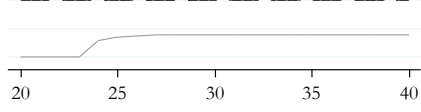

BG

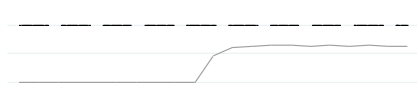

DK

$\mathrm{EE}$

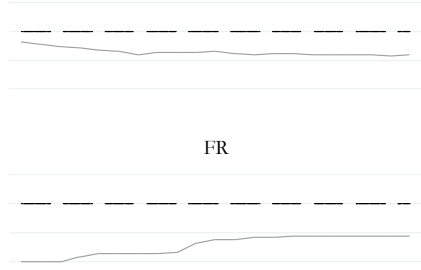

IS

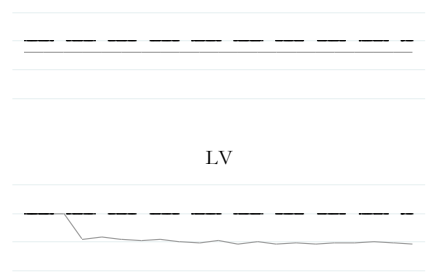

PL

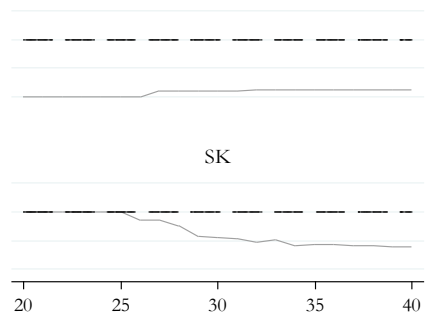

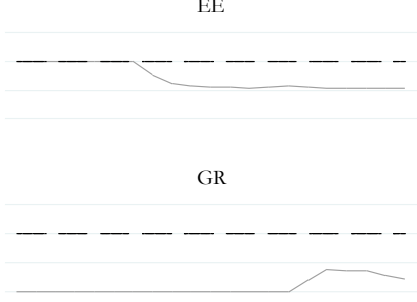

IT

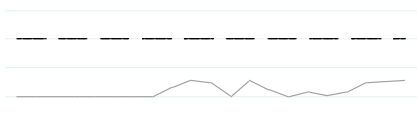

MT

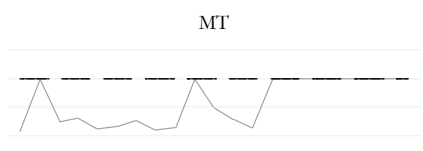

RO

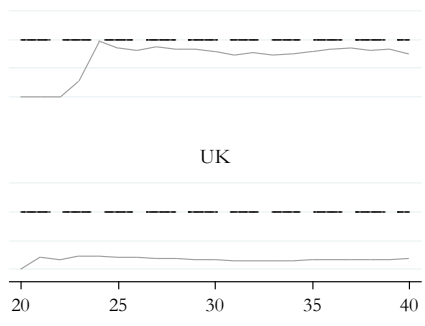

Figure 6 - Median Compensation rate over age in 2009

Source: EU-SILC \& Parental Leave Network, 2014.Note: Authors' own calculations. For abbreviations see Figure 2. 